\title{
Quantum Montessori: Learn Without Learning
}

Victor Selman, KSB (E-mail: vselman@american .edu), American University

Ruth Corey Selman, AMS Ngo/Dpi Representative to the United Nations

Elsie Selman, Consultant

Jerry Selman, Quantum-Era, Inc.

I think I can safely say that nobody under-stands Quantum Mechanics-Do not keep saying to yourself, if you can possibly avoid it, "How can it be like that?' because you will go down the drain into a blind alley from which nobody has yet escaped. Nobody knows how it can be like that.

The Character of Physical Law Richard Feynman (Nobel Laureate in Physics, 1968, for his contributions to Quantum Mechanics)

\begin{abstract}
Quantum Montessori is here referred to as the magic potion of Love Mnemonic, Intelligence of Love, Cosmic Education, Freedom of Choice and Movement, Kairos Time, Peace Stuff, and the counter-intuitive, all-connective spiritual logic of Quantum Mechanics.

This seminal paper attempts to explore natural quantum relationships in complex humanitas systems; in particular, to characterize states of entanglement in educational systems like Montessori, and to champion the quantum win/win approach to all education systems, where everybody learns--- without conscious learning. Using such quantum-mechanical notions and concepts as interdependent "entanglement," "superposition" "complementarity" and "frustration,"---the interconnectivity of the complete cycle of Quantum Learning is explored.
\end{abstract}

\section{Background}

$T$

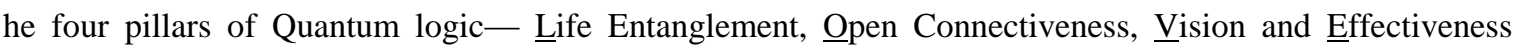
[mnemonic LOVE], --- integrate into our new "quantum-everything" world, setting off revolutions in natural philosophy---finding discontinuity in many fields of physics, forcing radical changes in even describing simple phenomena. Our old "status-quo" classical world [based on the pillars of Mechanical and Electromagnetic phenomena, and the Laws of Thermodynamics] only leaves "clouds" of paradoxes today. The general theme of the new Quantum logic is that questions about elementary processes lead to unifying concepts that may stimulate insight into more complex processes. Futurist Alvin Toffler has stated that the "illiterate of the $21^{\text {st }}$ century will not be those who cannot read or write. But those who cannot learn, unlearn and relearn [30].”

Quantum Education is the "natural" integrated way to learn, as there are no isolated "things"---only connections, networks, bonding relationships, linkages. Natural law is nature's way of applying means to ends. Montessori Education is the "natural" way to learn, to learn without learning. Natural learning, by definition, has to come easily and be user-friendly, and come at the "right" time---or it is not au natural. Love is the empowerment of normal development of the individual, recognizing the positive fundamental links between all humanity; negative

Readers with comments or questions are encouraged to contact the authors via email. 
influences of hatred, bigotry, and intolerance are, by definition, not natural. Children learn by following the natural flow of nature, which itself is ordered, cyclic, and meaningful. Montessori believed that the unfolding sequence of time [the spiritual aspects] and the deductive process of constructing the cosmos [the scientific mode] remains balanced, as in life, and that the process of unfolding is continuous.

In Greek, there are two words for time. The artificial 24-hour clock time is "Chronos" left-brained time, indicating the independence of events, amounts of time, masculine oriented time, (based on the myth of the Greek god Chronos who swallowed his children)---our chronometers, watches and clocks, our linear system of keeping time. For opening class at 9 A.M., and eating at noon, and having birthday parties and anniversaries, and putting dates on bridges, time capsules and tombstones. Natural time, called "Kairos" time is the feminine, right-brained time, more related to sequences of events, orderliness among events, the time when something occurs, the payoff time ---the time when mini-miracles happen, when expectations, hopes and love happens, when prayers are answered, when relationships, inter-connections and processes actually happen, on time, on natural time---as the time is just right. Children live in kairos time, and learn in kairos time---when their minds become totally absorbent. This is also the time when natural inner learning takes place on time with an inner cadence, every time we learn anything, learning on time from the inside out; not learning from the outside in - day-dreaming, imagining, praying--- in a spiritual, yet practical pathway to ubiquitous quantum relationships that, in many cases, challenge common sense.

According to Montessori [22], the order of nature is universal and particular, but also changeable---this makes the study of nature particularly engaging as children can discover the cause-and-effect principles that exist in nature's laws. Change, in this instance, includes the actual way we learn---the timeline for learning, retention duration and the paramount areas of what is now "learnable" in the current quantum paradigm. In a sense, educational entanglement - entailing peculiar connections between different objects — is actually a measure of how much quantum-ness the paradigm rules permit. Emerging are new quantum paradigms with new rules on entanglement (analogous to the laws of thermodynamics governing energy) addressing counterintuitive order and complexity in new systems.

Physicists argue that the $19^{\text {th }}$ Century was known for Machine development, the $20^{\text {th }}$ Century for the Information technologies---the $21^{\text {st }}$ Century would be characterized by Quantum technologies.

Attempts to explain Quantum Logic can be both weird and counter-intuitive, leading to such unreal statements like "It's never too late to have a happy child-hood," "You can have your cake and eat it, too," and "You can be in two places at the same time!" The bizarre state of being in two well-separated places at once has been visualized by imagining a large, shallow round-bottomed bowl with a marble simultaneously at opposite sides of the bowl, rolling from side to side and through itself at the very center [3]. The experiment provides a glimpse of quantum superposition states at a scale never seen before, of an ion's single remaining outer electron being in two internal quantum states- "up" and "down"--corresponding to different orientations of the spin of the electron. One Law of Quantum Mechanics allows the electron to be placed in a "superposition" of the two states, in which the two states both exist and are, in a sense, sort of stacked up upon one another. Until the particle is disturbed by an outside agent-a quantum tweak - there is equal probability that it is in either state, and thus it is considered to be in both states.

Quantum Mechanics derived from Quantum Theory allows "things" to be in two different places at the same time---strange as that idea may appear to be initially. But think of distant independent on-line interactive learning, or multiple locations. [See Carlos Castenada's meetings in his novels with his spiritual bruho Don Juan, who, no matter which of several locations in Mexico he decided to go to, he always finds him---or was it his co-located double? Don Juan says: "About half the time."] Quantum thinking changes all our current paradigms---exploding all our artificial limits on choice and possibility and hand-me-down constraints on diversity.

One of the seven Principles of Hawaiian Shamanism, delineated in Appendix A, is Pono: Effectiveness is the Measure of Truth---i.e., if some idea or model or approach works it is "true," and if it doesn't work it is "not true 
[14]." Another, Aloha: To love is to be happy with---defines the orientation of the shamanic approach. In fine, the criteria for quantum success are more complicated than in the classical (non-quantum) case.

The Montessori System "works"---therefore, it is effective, representing the closest example of workable Quantum Education, where the environment is prepared with didactic materials for the children to absorb the kernel of each concept at their own pace. Magical thinking "blurs the border between thinking and doing, between the inner space of imagination and the outer space of objectivity, confusing the volitional act of willing with causality, "states Dr. Leonard Shlain. Montessori children learn best without intrusive, damaging pedagogical machinations of "traditional" education, without rote learning, without consciously learning how to learn, by doing "hands on" subconscious visceral learning, and with "mind's on"---both the local and global implications of spiritual connectiveness.

Montessori teachers, "keepers of the environment," trained along Froebelian lines (with help from others, like Rousseau, Pestalozzi and Dewey) learn to move from a position of superiority to one of leadership and facilitating. Quantum thinking is an insightful, multiple entangled approach connecting our classical common-sense Newtonian world - where objects or things have definite identities - with our new Schrödinger quantum worldwhere things take on mysterious multiple realities simultaneously.

Millennial physicists have found that the classical Cartesian/Newtonian notion that matter consists of solid objects is not realistic. Both light and matter show some characteristics of particles and some characteristics of waves in one of the dilemmas of quantum theory. Why subatomic particles act both as waves and particles is still a puzzle. "You should not try to understand how quantum physics works," Feynman says, "All you can do is get a picture of what is going on. And the best way to get that picture is through 'the experiment with two-holes,' also referred to as Young's double-slit experiment," delineated in Appendix B.

According to Maria Montessori, " The first thing, then [is to] acquire... what one might call a "spiritual technique." And to attain it...to experience something akin to a religious conversion, for it will involve a "transvaluation of values." One novel down-the-quantum-rabbit-hole, innovative approach to learning is to oscillate between related dualistic aspects of the Quantum paradigm, bouncing from formal-type education presentations to subconscious/unconscious learning machinations---always focusing almost completely on the present state of quantum reality---keeping for reality reference only a small fraction of the ordinary dual state. Another, as a metaphor of a unit phenomenon emulating nature and the environment, so that all material learned viscerally, stays learned for an acceptable time period---yet has other serendipitous spin-offs, like improved self-confidence, creativity, emotional development, and freedom from limiting ideas

\subsection{Introduction}

Max Lerner states in his Foreword to Ferguson's The Aquarian Conspiracy [7]: "For the first time an American Renaissance is taking place in all the disciplines, breaking the boundaries between them, transforming them at their farthest reaches---where they all converge." The convergence in our point of view is via Quantum Montessori magic. The Montessori "Method" is based on the Triad of student-teacher-environment, with the student at the top vertex of the triangle, as co-creator of life. In her last book, Montessori wrote that the following words could substitute for her Method: "Means offered to deliver the human personality from the oppression of age-old prejudice regarding education." To change the world requires us to change ourselves, to change-change-change. To change our total perceptions, for example, that our contemporary schools are not designed for real learning, or actually about learning at all — but for avoiding mistakes, about gaining brownie points for approval and avoiding disapproval, disrupting our personal integrity The sad first time that one learns that idealism and hard work is stupid--“Don't screw up! Don't think! Do exactly what you are told---if something gets snafued, make doubly sure you don't get blamed, and always---repeat, always!-- make yourself look good---at any cost!---at all costs!”

Quantum global culture encompasses a much deeper change in our pattern of selflessness, trust and love, at all levels of our conscious/subconscious/unconscious perception; especially in the following four pillars of Quantum 
magic, supra, leading to the LOVE mnemonic. To reinforce the Quantum notions in this paper, the seven Principles of Hawaiian Shamanism, are invoked in Appendix A. The one principle repeated here is Pono: Effectiveness is the Measure of Truth---Montessori Education is true because it is effective, and it "works," ---including her special spiritual track on "Cosmic" education [31].

\subsection{Cosmic Education}

Cosmic Education, viewed by Montessori as the core of all learning experiences, focuses on the interconnectiveness of all life, that we are all related, that there is relationship between the developing child and the universe, which should be supported by the child's cosmic timeline experiences in school, linking the "good, old days" with the real-time limitless possibilities of cyberspace. Montessori's Cosmic Education Plan commences with this theme of creation, a sense of one's place in the universe---from the study of nature, which itself is ordered, cyclic, and meaningful. The unfolding sequence of time (spiritual aspects) and the deductive process of construction (scientific mode) remain balanced, as in life. The carbon-dioxide cycle is the most encompassing cycle used by Montessori to demonstrate nature's order. In this cycle, interdependence of life is revealed as plant and animal life connect. Humans, animals and fish breathe in oxygen and breathe out carbon dioxide. Simultaneously, the reverse activity is found in plants. As a result of this reverse activity in the carbon cycle, the oxygen level remains almost constant; thus, the air's gaseous balance assures human survival and gives a compelling illustration of the Cosmic Plan designed by Nature [31].

In addition to the recognition that Dr. Maria Montessori was a visionary, both in education and in psychology, she was also a physician, scientist and educator, credited with a worldview of peace, a cosmic view, which resonates today in the growing applicational field of Quantum Information thinking technologies connected to global peace and love for all children. "Let us give the child a vision of the whole universe." Children's intelligences become whole and complete because of the vision of the whole universe... and their interest spreads to all [nature], for everything is linked and has a place in the universe, in which the mind is centered."

What is the mind? How has "mind" been conceived by thinkers, philosophers, educators, psychologists, scientists, sociologists and theologians in the past two-and-a-half thousand years? Hampden-Turner [10] has divided this mindset exploration into nine levels, moving from narrower to broader concepts, and from earlier to later:

Beginning with historical and religious ideas of mind (including the Greeks, the Yin-Yang and Christianity); [he] then examines different psychoanalytic and existential concepts from Freud and Jung to Kierkegaard and Camus; the physiology of the brain; the creative mind from William Blake to Arthur Koestler; the psycho-social development (H. S. Sullivan, Erik Erikson); language and communication (Bertrand Russell. Korzybski and); Chomsky psycho-biology and cybernetics (Jonas Salk, Bertalanffy, Gregory Bateson); the paradigmatic mind (Marcuse, Kuhn and - Catastrophe Theory); and the structure and use of myth (Le'vi-Strauss, the Oresteia and Martin Luther King).

In Chinese the word "mind" is composed of two characters. The top part of the character means sound [literally, the sun rising], the bottom part of the character stands for heart. When we can hear the sun rising in our hearts---we will be free!

In the final analysis, "quantum" education looks to spiritual growth---the over-arching goal of awareness, beyond changes in subject matter or tutorial styles. Simultaneously, there is much interest in promising new alternatives and innovations for enhanced performance through self-modifications in the education community, exhibiting possibilities for new curricula and new instructional patterns---as well as a sharp break with traditional forms of pedagogical programming, even to "trick" students to think for themselves, believe in themselves, and to perform rigorous inquiry into the various disciplines [10]. Other than the Quantum Education focus on the bodymind-spirit approach, of making the mind more like the physical, or digital, and seeing the physical as having mental aspect now at the lowest quantum levels, there is no quick fix for the agenda of educational reform---to learn "on the run." To become--in this dangerous concrete jungle--a better, self-motivated, articulate person, with an instilled 
lifetime passion to help others - that is the hidden agenda of all education, particularly Montessori. Devoid of jargon, the credo the new Quantum Education paradigm delivers is the simplistic message of care and direction, yet reminding each of us that we have a hidden "wild card" of Love up our sleeve:

"Do the best wherever you are and be kind to yourself, to others, and to the planet Earth--- which is your home."

The "cosmic" approach, on the higher education levels, is also top-down, placing each student in touch with the whole of existence, top-to-bottom, zenith to nadir; nurturing the spirit of each student to function in two worlds simultaneously. The so-called external world of societies, institutions, family and friends; and the inner world of fantasies, imagery and the unconscious.

Our present learning environment has brought us to the brink of a dangerous, negative worldview. Since 9/11 we live in a No-No World, shutting out our creativity and imagination, circumventing decisions, losing our sense of helping to save the world.. We all construct the future by everything we think, feel and do, but we tend to do it unconsciously, still using a linear concept of Past-Present-Future, with its limited spatial and informational frontiers. The future of Quantum Education-all education --is beginning to look more and more like the mind/body/spirit Montessori philosophy of "education of the senses," or the Lockean model of the mind, "education of the intellect," which can only be filled by exposure to sensory stimuli and orderly experiences in the midst of urban chaos--- recombining and modifying these simple ideas, transforming them by cognitive quantum learning into visceral-type learning from the inside out.

Doctor Maria Montessori developed her "Programme" along two lines: Education of the Senses, and Education of the Intellect---a body/mind approach that is incorporated in modern quantum thinking, because it works---even in the poverty ghetto of San Lorenzo. Her Casa dei Bambino provided a good environment for children to live and learn, emphasis was placed on self-determination and self-realization. This entails developing a concern for others and discipline, which requires children to be engaged in exercices de la vie pratique (exercises in daily living). These and other exercises function like going up a flight of stairs, allowing the child to pick up the challenge at each level, and to judge their own progress. "The essential thing is for the task to arouse such interest that it engages the child's whole personality [22]." To which we like to substitute the word passion for interest. Amen.

\subsection{Education Of The Senses}

In 1964 the physicist Murray Gell-Mann borrowed a word from James Joyce's Finnegans Wake (*Three quarks for Muster Mark') and suggested that protons and neutrons are composed of "fundamental" objects called quarks [1]. Physicists call the smallest particle that holds the atom together the "charmed quark," and its symbol is a heart---the love energy that holds the universe together [1]. The fusion process of bringing atoms together is symbolic of increasing the energy levels [anecdotally] of love and healing that result from joining together in unity rather than splitting apart in separateness.

In addition to our five senses--hearing, seeing, tasting, touching, smelling-with which we experience the world directly, labeling the inputs of the world of our five senses [bird, song, music, soft, salty, etc.] is the "sixth sense." Once aware of the sixth sense, we believe there is something within us, some self, which causes this labeling, some "I" which is the seventh sense. In order to become free, in order to understand our true self, according to Buddha, we need to develop an eighth sense, which allows us to realize the illusory nature of labels and intellectual analysis of the sixth sense, and the concept of "I" of the seventh sense [29].

\subsection{Education Of The Intellect}

Howard Gardner, recipient of a MacArthur "Genius" Award, has proposed the various aspects of Intelligence. To his Multiple Intelligences [8], which now include Musical, Linguistic, Spatial, Intrapersonal, Logical/Mathematical, Inter-personal, Bodily/Kinesthetic, and Naturalist Intelligences---is added here another intelligence; possibly, the most important---Maria Montessiori's "Intelligence of Love." Unlike Gardner, whose 
intelligent list is a dynamic profile of time-changing intelligences, with overlapping definitions of intelligences and talents, the Intelligence of Love is natural, never changing, and all encompassing.

Dr. Montessori was deeply scientific in her outlook, too, although she did not bring science to bear on everything. Love-intelligence was not just intelligence on a high scientific level, but intelligence incorporated with love. The love was not just a sentimental, emotional love, it was really deep veneration, respect, sensitivity for all of life, as seen reflected in ...natural laws and in the wonders of ... Creation [22]. It behooves us to remember that Dr. Maria Montessori spent many years in India, during which time she befriended and studied Gandhi's satyagraha, non-violent resistance---the moral force which is always stronger than physical force. "Peace is organized love. War is organized hate. If we work as hard to bring about the organization of love as we do of hate, we would see the number of wars decrease and the toll of domestic violence." Montessori's "intelligence of love," is reminiscent of what we would like to call quantum love, connecting all positive disciplines under the sun for Peace ---it is mankind's secret weapon.

Quoting Ashley Montagu, "it requires, therefore, to be pointed out that intellect without humanitas, it is cold, superior, marvelous, and at the same time the most dangerous thing in the world. In whatever way man arrives at his beliefs, he uses his intellect to justify them and to give them an intellectual basis. Whether that basis is referred to the supernatural or the natural is beside the point here, what is to the point is that the intellect does the rationalizing, the cataloguing, the interpreting and the analyzing. It is therefore of the first importance to see to it that intellect is warmed by the fires of the human heart, the consciousness that the love of one's fellow men is beyond everything else the fundamental and primary quality of men, for without this love of his fellow men, man may be limitedly intelligent but he will not necessarily be humane, and it is because intelligence may be used or misused for any end whatsoever...that we must insist upon this prime requisite of humanity, of love of one's fellow men before all else [2I]."

A sharp distinction is here made between teaching--from the outside in--and learning --from the inside, emphasizing the mismatch between traditional teaching instruction and the conditions for effective learning. The dilemma for the education community is embodied in Stan Lee's satirical conundrum---The more information you have, the less you might know!

It is time to get education back to Montessori basics, and Peace is the most basic subject of all. Words like "giving" and "sharing" come up immediately. How difficult it is to teach children to share when we live in a nonsharing society. "When we achieve satori, or enlightenment, we gain the wisdom to hear our true self---the sound of the heart. We ultimately define ourselves by what we do in crises. The changes proposed for the quantum Montessori venue---opening people up to one another, building trust-- involve:

- $\quad$ A redefining of the purpose of education-To help others!

- $\quad$ A new cosmic curriculum which inevitably follows this spiritual redefinition, and

- An exploration of emerging paradigms for the inter relationship of other Quantum technologies with Triad of students/teachers/ environments.

Montessori education focuses also on connectedness, that we are all related, that there is relationship between the developing child and the universe, which should be supported by the child's cosmic timeline experiences in school, linking the "good, old days" with the real-time limitless possibilities of cyberspace. The Cosmic Education Plan commences with this theme of creation, a sense of one's place in the universe---from the study of nature, which itself is ordered, cyclic, and meaningful. The unfolding sequence of time (spiritual aspects) and the deductive process of construction (scientific mode) remain balanced, as in life.

The analogy for this cosmic view of educational duality might be the shamanic non-ordinary state of reality, which is the seat of ancient wisdom and our moral and spiritual potential, vis-à-vis, the ordinary state of everyday reality--introducing a spiritual perspective to the new, ubiquitous Love mnemonic emerging for the future of our dynamic millennium. If one can visualize the encompassing role of education as sharing and caring in the unfolding interrelated cosmology, future life may become more livable--- and more symbolic of peace and love. 
David Perkins, co-Director of Project Zero--a research group at the Harvard School of Education--states, "the world is not made up of well-defined problems. It is made up of complicated, messy, chaotic situations...for which we'd better have the skills to cope." Perkins et al have dubbed this coping ability "intelligence in the wild." Thinking "in the wild" means not just being able to solve a problem, but also recognizing that a problem exists in the first place, what that problem is and how much energy and effort should be invested in solving it. Street-smart Common Sense is a component of this additional kind of intelligence, but so are curiosity, open-mindedness and sensitivity to one's environmental surroundings. Perkins recommends that teachers ideally have students answer three types of questions---questions of exploration, about conclusions, and questions about connections. [See also www.theory.caltech.edu/people/preskill/ph229.]

\subsection{Summary}

It is noted in passim that since WWI, many Nobel prizes in Physics have been awarded to those who researched Quantum Mechanics, including Einstein, Dirac, Planck, Schrödinger, Feynman. About now, in discussing the Quantum mythology story, "Schrödinger's cat" arrives with the probability--considered by Erwin Schrödinger's [c.1935]--that a cat could be made to be both dead and alive at the same time---becoming a shorthand way to refer to a whole class of superposited states, and quantum particles in observed microscopic superposed

states. One of the resulting consequences of uncertainty is that you cannot specify the exact state of a particle without somehow interacting with it [6]. This famous paradox involving Uncertainty, known as "Who killed Schrödinger's Cat?" is shown in Appendix C, Schrödinger's Cat. Any interaction with the surroundings will destroy the superposition of the fragile states and the ion will collapse into a single entity (i.e., becomes decoherent).

Using such quantum-mechanical concepts as "entanglement," "super-position" and "frustration," this initial paper has attempted to investigate, with a modern new spin, the paramount cycle of Quantum Logic applied to Education---where everyone wins, or has a winning edge, instead of experiencing frustrating stalemates, and whether old deadlocks can be dissolved by Quantum Logic, resolving controversy and emotional states that have appeared to be "insuperable" by classical logic. The $20^{\text {th }}$ century had fragmented, broken up, and splintered the edifices of natural learning into little non-related packages of information. Information itself is not learning! The $21^{\text {st }}$ century is the time to put Humpty-Dumpty back together again!

If we define play as fun, and learning as play, we can include most of the electronic and computerized games that so fascinate us today. Because of their connection with new interactive problem-solving skills, quantum games may even come under the umbrella of the Montessori concept of "learning how to learn." In any event, Montessori helps children internalize the notion that the purpose of education is to help others. The structure of the classroom is a community where interaging provides support for all, in highly dependent situations.

"The starting point for a better world," the late Norman Cousins said, "is the belief that it is possible. The wild dream is the first step to reality. It is the direction-finder by which people locate higher goals and discern their higher selves [7]." Starting with this belief that it is possible, Quantum Education sermonizes that only by a deep rooted change in ourselves, followed by changes in our institutions-- social, educational, financial, political, ethical, legal, technological - can we go "where no man has gone before"--- from here to here. T. S. Eliot adds --- "The end of all our exploring will be to arrive where we started, and know the place for the first time."

\section{References}

1. Biddle, Wayne, From Alpha to Xrays, A Lexicon for the Science Watcher-Coming to Terms, Viking Press: New York, 1981, pp 92-3.

2. Christie, R. and F.L.Geis (Ed.), Studies in Machiavellianism. Academic Press, New York, 1970.

3. Collins, G. P., "Schrödinger's games: for quantum prisoners there may be no dilemma," Scientific American, vol. 282, No. 1, January 2000, pp 28-29.

4. Dertouzos, M., What Will Be: How the New World of Information Will Change Our Lives. Harper Edge (Harper Collins), San Francisco, CA 1997. 
5. Du, Jiangfeng. et al, "Experimental realization of quantum games on a quantum computer," Physical Review Letters, 88, 137902 (2002).

6. Dutch, S., Schrödinger's Cat is Alive or Dead, but not Both, and Definitely not Neither, University of Wisconsin, Green Bay, 3 Feb. 1998

7. Ferguson, Marilyn, The Aquarian Conspiracy: Personal and Social Transformation in the 1980s, Tarcher: Los Angeles, CA, 1980.

8. Gardner, Howard, Frames of Mind: The Theory of Multiple Intelligences, Basic Books, NY 1983

9. Gates, William H., Business @ The Speed of Thought: Using a Digital Nervous System, Warner Books, 1999.

10. Hampden-Turner, C., Maps of the Mind: Charts and Concepts of the Mind and Its Labyrinths, Mitchell Beazley: London, 1981.

11. Hubbard, B.M., Conscious Evolution: Awakening the Power of our Social Potential, New World Library, Novato, CA 1998.

12. Jonas, Gerald, Visceral Learning: Toward A Science of Self-Control. Viking Press: New York, 1973.

13. Keen, Sam, "Chronos \& Kairos Time" Chapter, Hymns to an Unknown God: Awakening the Spirit in Everyday Life, Banner Books, New York 1995.

14. King, Serge Kahili, Urban Shaman: A Handbook for Personal and Planetary Transformation Based on the Hawaiian Way of the Adventurer, Simon \& Schuster

15. Kuhn, T. S., The Structure of Scientific Revolutions, University Chicago, 1962.

16. Klarreich, Erika, "Playing by Quantum Rules," Nature, vol. 414, No. 6861, 15 November 2001, pp. 244245.

17. ay, Gerald G., Care of Mind, Care of Spirit: A Psychiatrist Explores Spiritual Direction. Harper San Francisco (Harper Collins): CA, 1992.

18. Meyer, David, in Physics News Update, The American Institute of Physics, Bulletin of Physics News, No. 411, January 19, 1999

19. Milburn, G., The Feynman Processor: Quantum Entanglement and The Computing Revolution, Helix Books Series, Perseus Books,

20. McLaughlin, C. \& G. Davidson. Spiritual Politics: Changing the World From the Inside Out, Ballantine Books: New York, 1994.

21. Montagu, Ashley, Immortality, Grove Press: New York, 1954.

22. Montessori, Maria, To Educate the Human Potential, Kalakshetra: Madras, India 1948.

23.

24.

25.

26.

27.

28. Phillips, B. S., Worlds of the Future: Exercises in the Sociological Imagination, Merrill Publishing: Columbus, OH, 1972.

29. Shapiro, D. H., Jr. Precision Nirvana, Prentice-Hall, Englewood Cliffs, NJ, 1978.

30. Toffler, Alvin, The Third Wave. William Morrow: New York, 1980.

31. Trudeau, Sister C.M., Montessori's Years in India, Doctoral Dissertation, University of Hawaii at Manoa, Hawaiian Printing Corp., HI, 1984. [American Montessori Society.]

\section{Appendix A}

Seven Shamanic Principles And Their Corollaries

Source: King, Serge Kahili, Urban Shaman: A Handbook For Personal And Planetary Transformation [Based On The Hawaiian Way Of The Adventurer]. Simon And Schuster (Fireside): New York, 1990.

IKE---The World Is What You Think It Is

Corollary: Everything is a Dream All Systems are Arbitrary 
KALA---There Are No Limits

Corollary: Everything is Connected Anything is Possible. Separation is a Useful Illusion

MAKIA---Energy Flows Where Attention Goes

Corollary: Attention Goes where Energy Flows Everything is Energy

MANAWA---Now Is The Moment Of Power

Corollary: Everything is Relative Power Increases with Sensory Attention

ALOHA---To Love Is To Be Happy With

Corollary: Love Increases as Judgment Decreases Everything is Alive, Aware and Responsive

MANA---All Power Comes From Within

Corollary: Everything has Power Power comes from Authority

PONO---Effectiveness Is The Measure Of Truth

Corollary: There is Always another Way to do Anything.

\section{Appendix B}

Young's Double-Split Experiment [A.K.A. The Experiment With Two-Holes]

"This is a phenomenon which is impossible, absolutely impossible, to explain in any classical [that is, common sense] way, and which has in it the heart of quantum mechanics. In reality, it contains the only mystery...the basic peculiarities of quantum mechanics." Richard Feynman, Lectures in Physics.

Thomas Young, the $19^{\text {th }}$ Century British physicist involved in this experiment involved light in his version, and for the next hundred years it was seen as proof that light was a wave. One pure color of light (which is usually interpreted as meaning a single wavelength of light) is shone through a hole in a screen, and on to another screen in which there are two holes, or sometimes two long, narrow slits. Two sets of light waves spread out, one from each of the holes, like ripples on a pond, and (just like two sets of ripples produced by dropping two stones in a still pond simultaneously) they interfere with one another. The result is that when the light arrives at the final screen in the experiment, it makes a characteristic pattern of light and dark stripes, called interference fringes. One key feature of the interference pattern is that it is brightest at a point midway between the two holes, where the two waves add together.

But in the $20^{\text {th }}$ Century, first Max Planck (on black body radiation) and then Albert Einstein (on the photoelectric effect) showed that light, in some circumstances, had to be treated as if it were a stream of little particles, light quanta now known as photons. The way particles pass through two holes in a wall is very different, in the everyday commonsense world, from the way waves behave. The discovery that light can behave like a wave or like a particle is an example of wave-particle duality. By the 1920s it was clear that electrons, which were traditionally regarded as particles, could also behave like waves, in another example of wave-particle duality. Now we know in the Alice-in-Wonderland-like quantum world as waves are particles, and all particles are waves.

The electron version of Young's experiment was carried out in 1987 by Japanese researchers who fired electrons through two holes, recording their arrival on the other side on a detector screen [like a TV screen]. The special feature of this screen is that each electron makes a spot of light on the screen, and the spot stays there as other electrons arrive, each making its own spot, so that gradually they build up a pattern on the screen. Each electron leaves a "gun" on one side of the experiment as a particle. Each electron arrives at the detector on the other side as a particle, and makes one small spot on the screen. But as thousands of electrons are fired through the experiment, one at a time, the pattern that builds up on the screen is the classic interference pattern associated with waves. 
This is doubly mysterious. Not only are the electrons leaving and arriving as particles, but somehow traveling as waves (as if each electron passes through both holes in the experiment and interferes with itself), but they seem to "know" the past and the future as well. If thousands of electrons traveled together through the experiment, it might be easy to understand that they could jostle one another into an interference pattern. But only one electron passes through the experiment at a time, and somehow chooses its path on the screen on the other side so that the pattern that gradually builds up is the classic interference pattern. How can each electron possibly "know" its rightful place in the pattern?

And there's more. If one of the two holes is blocked off, the electrons form one blob of spots on the screen behind the remaining hole; equivalent to the pile of rocks you would get by throwing them through a hole in the wall. With the other hole open and the first one closed, you get a blob on the screen behind the hole. But with both holes open, the interference pattern emerges, with the brightest part of the pattern on the line midway between the holes. An individual electron, passing through just one hole of the experiment, seems to be aware whether or not the second hole is covered up, and to adjust the trajectory accordingly.

[FEYNMAN ADDS: “DON'T LOOK FOR THE ANSWER TO THAT QUESTION HERE, OR ANYWHERE ELSE!]

\section{Appendix C \\ Schrödinger's Cat.}

[This is a good example of a "thought experiment," a device used in physics to investigate the consequences of hypotheses [4]. It is a heuristic device that illustrates some of the paradoxes of Quantum Mechanics while sharpening our inquiries.]

On 7 June 1935, Erwin Schrödinger wrote to Albert Einstein congratulating him on what is now known as the EPR Paper, a famous problem in the interpretation of Quantum Mechanics. He then published his RubeGoldberg cat-in-the-box idea, which was to become one of the most celebrated paradoxes in Quantum Theory. [Unfortunately, feline lovers have taken this example too literally.]

A cat is placed in a box, together with a radioactive atom. If the atom decays, and the Geiger counter detects an alpha particle, the hammer hits a flask of prussic acid (HCN), killing the cat.

The paradox is the simple coupling of classical and quantum domain. Before the observer opens the box, the cat's fate is tied to the wave function of the atom, which is a superposition of decayed and undecayed states. Thus, Schrödinger said- "The cat must itself be in a superposition of dead and alive states before the observer opens the box, 'observes' the cat and 'collapses' its function." 